South African Journal of Geomatics, Vol. 7. No. 3, November 2018

\title{
Review of the Use of Remote Sensing for Monitoring Wildfire Risk Conditions to Support Fire Risk Assessment in Protected Areas
}

\author{
Olga Dipuo Molaudzi 1, 2,; Samuel Adewale Adelabu 1,2, \\ ${ }^{1}$ Department of Geography, University of the Free State, Qwaqwa Campus, Phuthaditjhaba, \\ South Africa, adelabusa@ufs.ac.za \\ ${ }^{2}$ Afro-Montane Research Unit, University of the Free State Qwaqwa Campus, Phuthaditjhaba, \\ South Africa
}

\section{DOI: http://dx.doi.org/10.4314/sajg.v7i3.2}

\begin{abstract}
Fire risk assessment is one of the most important components in the management of fire that offers the framework for monitoring fire risk conditions. Whilst monitoring fire risk conditions commonly revolved around field data, Remote Sensing (RS) plays key role in quantifying and monitoring fire risk indicators. This study presents a review of remote sensing data and techniques for fire risk monitoring and assessment with a particular emphasis on its implications for wildfire risk mapping in protected areas. Firstly, we concentrate on $R S$ derived variables employed to monitor fire risk conditions for fire risk assessment. Thereafter, an evaluation of the prominent RS platforms such as Broadband, Hyperspectral and Active sensors that have been utilized for wildfire risk assessment. Furthermore, we demonstrate the effectiveness in obtaining information that has operational use or immediate potentials for operational application in protected areas (PAs). RS techniques that involve extraction of landscape information from imagery were summarised. The review concludes that in practice, fire risk assessment that consider all variables/indicators that influence fire risk is impossible to establish, however it is imperative to incorporate indicators or variables of very high heterogeneous and "multi-sensoral or multivariate fire risk index approach for fire risk assessment in $P A$.
\end{abstract}

Keywords: Protected Areas, Fire Risk conditions; Remote Sensing, Wildfire risk assessment

\section{Introduction}

Approximately 133,000 Protected Areas (PAs) worldwide covering over 12\% of the land surface of terrestrials biomes emerged as the cornerstone of efforts towards conservation (Nagendra et al., 2013). Protected Area is a clearly defined geographical space, recognized, dedicated and managed through legal or other effective means to achieve the long-term conversation of nature with associated services and cultural values (International Union for Conservation of Nature (IUCN), 2015). Fire is considered as a major factor in the environmental transformation of ecosystems (Food and Agricultural Organisation, 2007). On the other hand, fire is recognized as an important ecological process used as a management tool for maintaining healthy ecosystems particularly in PAs. However, 
fires in PAs are paradoxical (Pereira et al., 2012), in that if properly planned, desired outcomes such as regulating fuel accumulations, regeneration of vegetation by removing fungi and microorganisms, disease and insect control, receiving more energy through exposure to solar radiation, mineral soil exposure and nutrients release are achieved (Bond et al., 2005, Pausas and Paula, 2012). In contrast, unwanted or uncontrolled fires can be destructive or result in ecological disturbance causing bush encroachment, invasion by alien plants, reduction in water yield and loss of biodiversity (Brown and Smith, 2002, Jhariya and Raj, 2014). It is always a challenge to reconcile the fire management goals that relate to safety on one hand to the maintenance of ecosystem health as acknowledged by Van Wilgen et al. (2011). This is because approaches to fire management in PAs have focused on encouraging particular fire patterns in the absence of sound monitoring and assessment of fire risk conditions (Mbow et al., 2004). Hence, it is imperative to develop an effective and efficient fire management plan to reduce these losses and optimize the benefits from fires. Towards the achievement of this goal, fire risk assessment has been commended as one of the major components of integrated fire prevention and management (Chuvieco et al., 2004, Leblon et al., 2012, Yebra et al., 2008).

Different systems or techniques have been used to monitor and assess fire risk conditions in the past. For instance, conventional methods such as (i) field reconnaissance (traversing the landscape on the ground and recording the extent of similar fuel conditions in notebooks or on paper maps); (ii) directly mapped fuel from aerial photo interpretation and (iii) an ecological modelling approach which uses environmental gradients to create fuel maps for monitoring vegetation conditions have been applied for fire risk assessment (Arroyo et al., 2008, Keane et al., 2001). Field sampling involving oven drying methods such as gravimetric sampling (involves comparing the difference in weight of sample from the field and its oven drying) (Aguado et al., 2007) and analogue sampling methods (involving the repeated weighing of a sample exposed to field conditions) such as calibration of a sticks known as hazard sticks (Yebra et al., 2013) were employed to measure fuel moisture content. In addition, Fuel moisture content (FMC) has been indirectly measured using meteorological variables through the analysis of atmospheric characteristics from which fuel water status is estimated (Yebra et al., 2008). Although these conventional methods are considered to be reliable, accurate and useful for calibration and final product accuracy assessment of derived from remotely sensed data (Arroyo et al., 2008), they however suffer from numerous drawbacks. For example, field measurements are primary based on point-source data. In general, to forecast fire danger rating over a large geographic regions, point data must be interpolated (Leblon et al., 2012) which would be quite expensive and laborious in terms of data collection and its processing (Chowdhury and Hassan, 2015). Therefore, Leblon (2005) argued that the accuracy of ratings may be limited by the density of point data and interpolation methods that generally does not account for fine-scale variations in environmental conditions.

In the past three decades, passive and active remote sensing systems have been employed to address the spatial and temporal interpolation limitations associated with conventional methods with 
obvious advantage of spatial and regular temporal coverage (Dalponte et al., 2009). Subsequently, several operational global, regional \& national monitoring system products and early fire-warnings were developed based on remote sensing and Geographic Information System (GIS). Among the existing products, the most prominent ones are Global Fire Monitoring Centre (GFMC) of the United Nations International Strategy for Disaster Risk Reduction (UN/ISDR), Global Observation of Forest and Land Cover Dynamic (GOFC)/GOLD, the Early Warning System for Wildfire (EWSFire) component of Canadian Forest Fire Danger Rating System (CFFDRS), the European Forest Fire Information System (EFFIS) and the South African Advanced Fire Information System (AFIS) as well as the MODIS Rapid Response System (Ballester, 2007, Vorster and Jordaan, 2014).

With the consideration of the characteristics of various remote sensing systems developed over the past decades, the significant mandate of PAs (irrespective of vegetation cover) and the impacts of fire as well as heterogeneity of environmental factors that influence vegetation flammability are significant. Questions such as how to ensure the long-term sustainability of the PAs with complex landscapes where diverse conflicts of interest meet, i.e. nature conservation and tourism still persist (Aretano et al., 2015). Furthermore, effective application of fire as an ecological process to develop sound fire management strategy and hence monitoring of fire risk conditions for fire risk assessment based on the remote sensing technology has become critical within PAs management. Therefore, summaries and comparisons of different remote sensing approaches are urgently required and indispensable for PAs management in order to better understand the mechanisms of interactions between vegetation characteristics and its environmental conditions. Thus, the objective of this manuscript is to review different remote sensing data and techniques that have been used for predicting and monitoring fire risk conditions and its implication for fire risk assessment and mapping in PAs.

\section{Remote Sensing in Monitoring Vegetation Conditions for Fire Risk Mapping}

In wildfire risk assessment, remote sensing (RS) derived products assist in the elaboration of vegetation or fuel maps (type \& structural traits), topography and land use in order to create a permanent or static database. Furthermore, RS derived products are used to determine the meteorological conditions and vegetation or fuel properties (biomass \& moisture) in real time and in a dynamic way in order to provide the risk indexes (Calle and Casanova, 2008). Several studies have demonstrated the existence of relationship between fire and vegetation characteristics (Lozano et al., 2007, Schneider et al., 2008) as well as the relationship between remote sensing and these variables or indicators (Arroyo et al., 2008). However, in order to understand the usefulness of remote sensing in monitoring and mapping wildfire risk conditions, it is crucial to understand the relationship between environmental conditions and fire occurrence following protocols as suggested by Chowdhury and Hassan (2015). In doing so, more information on remotely sensed data used to quantify vegetation flammability will be discussed. 


\subsection{Remote sensing derived variables/indices for monitoring fire risk conditions}

Generally, remotely sensed vegetation and water indices have been used to assess the extent of vegetation flammability conditions and to understand the fire risk conditions. In simplicity, Chowdhury and Hassan (2015) on the basis of environmental conditions broadly categorised these indices into (i) vegetation greenness, (ii) meteorological variables; (iii) surface wetness conditions and (iv) vegetation wetness conditions.

Vegetation greenness-related indices have been immensely used for fire risk assessment under the assumption that the chlorophyll content of vegetation decrease in proportional to the vegetation water content based on the spectral signature of vegetation greenness expressed in Red (R) and Near Infrared (NIR) portions of the spectrum (Table 1). The internal structure of healthy leaves acts as an excellent diffuse reflectors of near-Infrared reflectance wavelengths and therefore measuring and monitoring near-infrared reflectance (NIR) is used to determine the health of the vegetation (Barroso and Monteiro, 2010). The healthy vegetation shows a very low reflectivity in the Visible Band of the electromagnetic spectrum (0.4 -0.7 micrometres). While unhealthy vegetation lack of chlorophyll in their leaves makes the spectral curve of reflectivity move significant towards the red colour (Calle and Casanova, 2008).

The Normalized Difference Vegetation Index (NDVI) also known as "continuity index is calculated as function of surface reflectance of red $(0.6-0.70 \mu \mathrm{m})$ and NIR $(0.70-0.90 \mu \mathrm{m})($ Huete et al., 2002). No doubt, that NDVI is one of the immensely utilized and well-known VI in measuring both morphological and physiological characteristics of the vegetation conditions for estimation and monitoring fire risk conditions for fire risk assessment and mapping with PAs. For example, NDVI have been used to distinguish shrub height in order to distinguish shrub for description of fuel conditions (Riaño et al., 2007), to evaluate vegetation cover or canopy cover (Falkowski et al., 2004); Leaf Area Index (LAI)(Yebra et al., 2008); biomass (Saatchi et al., 2007, Sannier et al., 2002, Verbesselt et al., 2006b); phenology (Van Wagtendonk et al., 2003), and fraction of Absorbed Photosynthetic Active Radiation ( fAPAR) and also a fractional of vegetation cover (fPAR) (Jia et al., 2006a).

However, other indices based on R \& NIR exhibit stronger relationships with vegetation or fuel conditions than NDVI in both protected and unprotected areas. For example, Soil Adjusted Vegetation Index (SAVI) that take into account the influence of bare, unsaturated soil backgrounds in order to minimise soil noise (Huete, 1988, Moreau et al., 2003). While Enhanced Vegetation Index (EVI) is an example of optimized spectral band combinations that aim to minimize VI biases from canopy background and aerosol variations and outperformed NDVI over high biomass area since it does not saturate easily and it is recommended for tropical dense vegetation (Huete et al., 2002, Huete, 2012). Visible Atmospherically Resistant Index (VARI) was developed for estimating green vegetation fraction since it minimizes the sensitivity to atmospheric effects (Stow et al., 2005). Global Environmental Monitoring Index (GEMI), one of the hybrid vegetation indices for extraction of 
biomass data was introduced because is good for vegetation canopy of low cover (Bisquert et al., 2014, Zhang et al., 2005).

Table 1. Selected vegetation greenness indices in monitoring fire risk conditions in the literature

\begin{tabular}{lll}
\hline Indices & Formula & Reference \\
\hline SR & $S R=\frac{N I R}{R}$ & (Falkowski et al., 2004) \\
NDVI & $N D V I=\frac{N I R-R}{N I R+R}$ & (Rollins et al., 2004); (Bisquert et al., 2014); \\
& & (Wang et al., 2013) \\
SAVI & $S A V I=(N I R-R) /(N I R+R+L) *(1+L)$ & (Verbesselt et al., 2006b) (Huete et al., 2002) \\
VARI & $V A R I=\frac{G r e e n-R}{\text { Green }+R-B}$ & (Gitelson et al., 2002) (Schneider et al., 2008); \\
& GEMI $=\eta(1-0.25 \eta)-\left(\frac{R-0.125}{1-R}\right) W h e r e$ & (Stow et al., 2005); \\
GEMI & $\eta=2\left(N I R^{2}-R^{2}\right)+1.5 R 2+0.5 N I R 2 / R+N I R+0.5$ & (Pinty and Verstraete, 1992); (Bisquert et al., \\
& 2014) \\
EVI & $E V I=\frac{2.5(N I R-R)}{N I R+6 R-7.5 \text { Blue+1 }}$ & (Huete et al., 1984); (2002); (Mildrexler et al., \\
& & 2007); (Bisquert et al., 2014) \\
\hline
\end{tabular}

Remote Sensing meteorological variables such as Surface Temperature $\left(T_{s}\right)$, Air Temperature $\left(T_{a}\right)$ and Relative Humidity (RH) on the other hand are used as indicators in monitoring and analysis of fire risk conditions. Ts computed from thermal infrared bands have been found to provide valuable information on fuel temperature, vegetation moisture status and air humidity over the surface (Leblon et al., 2012, Wang et al., 2013). Manzo-Delgado et al. (2004) used $T_{\mathrm{s}}$ variable as the fire risk indicator over the temperate forest in Central Mexico. The results showed that $\sim 60 \%$ of the fire took place when they were between $8{ }^{\circ} \mathrm{C}$ and $15^{\circ} \mathrm{C}$. Since, Ts is too sensitive to weather conditions, the difference between $T_{s}$ and $T_{a}$ is regarded as a better spectral index to monitor vegetation water status than $T s$ alone (Leblon et al., 2012).

Keetch-Byram Drought Index (KBDI) is one of the fire/drought index that is derived from meteorological data. It has been used to estimate fire risk conditions from meteorological data such as daily maximum temperature, daily total precipitation and minimum annual precipitation (Keetch and Byram, 1968). KBDI is strongly related to vegetation water content since most of the vegetation moisture stress are caused by soil moisture deficiencies (Aguado et al., 2003). It has been recommended for operational use in South Africa (Dimitrakopoulos and Bemmerzouk, 2003) as an indicator of dead fuel moisture content. Its utility has been effectively demonstrated on shrub species or herbaceous fuel moisture content (Riaño et al., 2005).

Surface Wetness Conditions have been monitored based on the concept of evapotranspiration (ET). ET is described as the loss of water from the Earth's surface to the atmosphere by the combined processes of evaporation from open water bodies, bare soil and plant surfaces, and transpiration from vegetation or any other moisture containing living surface (Li et al., 2009). RS-based ET estimation methods can be broadly categorised into the following groups based on the following principles (i) 
water balance,(ii) surface energy balance, (iii) vegetation indices and (iv) hybrid approaches based on vegetation indices and $\mathrm{T}_{\mathrm{s}}$ (AghaKouchak et al., 2015).

In fire risk assessment, hybrid approaches have been widely applied whereby Surface Temperature $\left(\mathrm{T}_{\mathrm{s}}\right.$ ) has been incorporated with vegetation greenness variables to indirectly estimate the surface wetness condition as an indicator for wildfire risk. This approach explores the complementary of thermal and visible/near infrared wavelengths in order to obtain information about heat energy and the water status of the surface related to water stress (Sandholt et al., 2002). For example the ratio of NDVI/Ts (Aguado et al., 2003, Prosper-Laget et al., 1995); and EVI/Ts (Mildrexler et al., 2007). The incorporation of NDVI and $\mathrm{T}_{\mathrm{s}}$ assists in justification for the influence on the ground cover rate over the composite $T_{\mathrm{s}}$ measured by the sensors (Leblon et al., 2012). This resulted to the derivation of more indices such as Stress Index (SI) (Vidal et al., 1994), Water Deficient Index (WDI) (Moran et al., 1994, Vidal and Devaux-Ros, 1995); Temperature -Vegetation Wetness Index (TVWI) (Akther and Hassan, 2011).

WDI developed by Moran et al. (1994) estimated by the ratio of LE/LEp by using land surface temperature and ambient $T_{a}$ and has been used for partially vegetated covers. $L_{p}$ is the latent heat flux for potential evapotranspiration rate (Rahimzadeh-Bajgiran et al., 2012) and has a potential for evaluating evaporation rate and relative field water deficit for both full cover and partially vegetated sites (Verbesselt et al., 2002). TVWI was developed by Sandholt et al. (2002) as a simplification of WDI by interpreting the relationship between LST and NDVI in terms of soil moisture.

Although these evapotranspiration-concept indices are widely used they are acquired through thermal inertia approach. These indices only yield satisfactory results in soils with little vegetation cover since the latter reduces the temperature differences between day and nights and in order to determine the moisture in a concrete point it is necessary to have the day and night temperature in a cloud -free images (Calle and Casanova, 2008).

In general, quantification of vegetation/fuel cover moisture has been conducted through the measure of fuel moisture content or the Equivalent Water Thickness (EWT) defined as ratio between the quantity of water and the leaf area (Leblon et al., 2012) and Relative Water Content (RWC) compares the water content of a leaf with the maximum water content at full turgor (Ceccato et al., 2002, Wang et al., 2013). It is regarded as an extremely essential vegetation condition parameter since it ha as an inverse relation with ignition probability owing to the fact that the energy necessary to start a fire is used up in the process of evaporation even before the fire starts to burn (Dimitrakopoulos and Bemmerzouk, 2003). Moreover, fuel cover moisture dilutes volatiles and excludes oxygen from the combustion zone. However, the water content also affects fire propagation as the source of the flames as it reduced with humid materials and therefore reduce vegetation flammability (Chuvieco et al., 2009 ). Most studies have directly measured vegetation water content by utilizing water absorption channels in the SWIR and contrasting it with NIR channels to account for the variations in reflectance due to leaf internal structure (Dalponte et al., 2009) (Table 2). The uncertainties arise in estimating vegetation water content using NIR - SWIR indices because they cannot completely remove 
background soil effects (Gao, 1996). Therefore, a new index called Normalized Multi-Band Drought Index (NMDI) was introduced by combining multiple, rather than one SWIR for monitoring soil and vegetation moisture conditions (Wang et al., 2008).

Table 2. Selected vegetation wetness condition indices derived as a function NIR and shortwave infrared (SWIR) to determine the fuel moisture content for fire risk

\begin{tabular}{|c|c|c|}
\hline Indices & Algorithm & References \\
\hline $\begin{array}{l}\text { Normalized Difference Water } \\
\text { Index }\end{array}$ & $N D W I=\frac{\rho N I R-\rho S W I R}{\rho N I R+\rho S W I R}$ & (Gao, 1996); (Verbesselt et al., 2006a) \\
\hline $\begin{array}{l}\text { Global Vegetation Moisture } \\
\text { Index }\end{array}$ & $G V M I=\frac{[(\rho N I R+0.1)-(\rho s w i r+0.2)]}{[(\rho N I R+0.1)+(\rho s w i r+0.2)]}$ & $\begin{array}{l}\text { (Wang et al., 2013); (Ceccato et al., } \\
\text { 2002) }\end{array}$ \\
\hline $\begin{array}{l}\text { Normalized Differences } \\
\text { Infrared Index }\end{array}$ & $N D I I=\rho N I R-\frac{\rho S W I R}{\rho N I R}+\rho S W I R$ & $\begin{array}{l}\text { (Hunt and Rock, 1989);(Chuvieco et } \\
\text { al., 2002) }\end{array}$ \\
\hline Moisture Stress Index (MSI) & $M S I=\frac{\rho S W I R}{\rho N I R}$ & (Sow et al., 2013) \\
\hline $\begin{array}{l}\text { Simple Relation Water Index } \\
\text { (SRWI) }\end{array}$ & $S R W I=\frac{\rho N I R}{p S W I R}$ & (Gao, 1996); (Sow et al., 2013) \\
\hline $\begin{array}{l}\text { Normalized Multi Drought } \\
\text { Index (NMDI) }\end{array}$ & $N M D I=\frac{\text { band } 2-(\text { band } 6-\text { Band } 7)}{\text { band } 2+(\text { band } 6+\text { Band } 7)}$ & (Wang et al., 2013), \\
\hline
\end{tabular}

All of these RS derived variables have been used as indicators for fire risk conditions in fire risk assessment and mapping either individually or integrated with other variables (Calle and Casanova, 2008). While some obtained a sound correlation with fire occurrences, other indices and variables yield to a low correlation or dissimilar results among different ecosystems. With the acknowledgement of limitations related to VI, the researchers have developed and improved techniques by using hyperspectral, hyper-temporal and microwave remote sensing derived indices to characterize the vegetation.

\section{Remote Sensing Platforms for Monitoring, Assessment and Mapping Wildfire Risk}

Fundamentally, the choice of remote sensing platform will depend on the amount of information or variables that are available to create a fire risk index or model to a sufficient degree of accuracy and to monitor changes (Kennedy et al., 2009). Furthermore, Nagendra et al. (2013) highlighted three critical aspects that should be considered in the selection of datasets, i.e. (i) Scale (spatial and temporal), (ii) the adequacy or quality of spatial datasets and (iii) dataset sources. Different RS instruments and platforms have been utilized in the past decades for acquiring imagery to extract indicators for monitoring fire risk conditions for wildlife risk mapping with differing success. Thus, a review of the prominent remote sensing platforms that have been utilized for obtaining information that have operational uses or immediate potentials for operational application in PAs management are explored in the following section. 


\subsection{Broadband sensors}

Remote sensing broadband sensors imageries have been found to effectively monitor vegetation traits for fuel type, fuel load or biomass mapping and fuel moisture content in wildfire risk assessment for PA. Landsat and other coarse, medium to high spatial resolution sensors have relative good spatial and spectral resolution essential for fire risk assessment and mapping. The $30 \mathrm{~m}$ spatial resolution of Landsat sensors allows spatial detail to be captured at a scale appropriate for monitoring vegetation structure and composition (Willis, 2015) and good spectral resolution of seven bands. Erten et al. (2004) used Landsat TM images taken before and after the forest fire in Gallipoli Peninsula Historical National Park in Spain to map burned area and to estimate vegetation moisture context in conjunction with topographic maps, forest type map, vegetation map, elevation, slope, aspect, topographic map and climate data (average, wind, rainfall data and temperature to determine fire risk areas. The authors concluded that remote sensing is a useful tool to determine fire risk area and could support fire management activities. Banu et al. (2014) employed Landsat 8 imagery to estimate the vegetation moisture in combination with other variables for the cartographic wildfire risk areas in National Park Domogled- Cerna Valley in Romania. Because of its revisiting time of 16 days, the operativeness for estimation of the FMC in real time is ruled out (Calle and Casanova, 2008) and the constraints to cover a cloud-free landscape in a large area, it is difficult to reveal key characteristics of the plant where vegetation is highly dense or saturated (Mbow et al., 2004).

As an alternative, Advanced Very High Resolution Radiometer (AVHRR) sensors of National Oceanographic and Atmospheric Administration (NOAA) with a daily temporal resolution have demonstrated to be effective for mapping fire risk (in particular dynamic fire risk map) through the study of water stress. Sannier et al. (2002) used NOAA- AVHRR to estimate the biomass for wildfire risk assessment in Etosha National Park. The study had demonstrated the suitability of AVHRR for measuring biomass of grassland in the Park. Maselli et al. (2003) used past-fire occurrence data and NOAA-AVHRR NDVI data of 16 years (1985-2000) to estimate fire risk in Tuscany (Central Italy). AVHRR has an image archive with long history, it is useful to study long-term changes of vegetation however its utility has been restricted because its often introduce substantial errors at the various stage of processing and analyzing (Xie et al., 2008).

Another sensor that has been applied in wildfire risk mapping is Système Pour I'Observation de la Terre (SPOT) managed by French Space Agency (CNES). Verbesselt et al. (2006a) used SPOT VEGETATION time-series to monitor the vegetation biomass and water content to improve fire risk assessment in the savannah ecosystem of Kruger National Park in South Africa. This study illustrated the importance for the combination of both vegetation biomass and vegetation water content for fire risk assessment. The study concluded that monitoring of vegetation biomass and water content with SPOT VGT provided a more suitable tool for fire management and suppression compared to satellitebased fire risk assessment methods only related to vegetation water content.

Fire risk assessment and mapping have been extensively investigated using Moderate Resolution Imaging Spectro-radiometer (MODIS). For example, Yebra et al. (2008) estimated FMC of 
Mediterranean vegetation species using a 5-year time (2001 -2005) of Terra MODIS for fire risk assessment in the Cabañeros National Park (Central Spain) offering reasonable result with better performance on grassland ( $91 \%$ \& $89 \%$ ) than shrublands (73\% and $84 \%$ ). Dlamini (2011) used MODIS Terra and Aqua satellites' active and burnt area data to analyse and process the biophysical and socio-economic variables to generate a fire risk map of the Kingdom of Swaziland. Accuracy assessment and comparison of the fire risk maps resulted in $93.14 \%$ and $96.64 \%$ accurate respectively, showing adequate agreement between risk maps and the existing data. Although the model is valid for generalized national planning and assessment purposes the author suggested that more work is needed to improve data collection and integration for practical application in near realtime fire risk analysis.

Furthermore, the utility of MODIS data was found to be useful for estimating herbaceous water content and for monitoring the drying process of herbaceous vegetation in the management of savannah fire by the study conducted by Sow et al. (2013) at Senekal. In comparison with other broadband sensors, MODIS data are available at a significantly higher temporal resolution (daily) with the spectral bands available in Landsat data. However, MODIS imagery has limitations for monitoring land cover changes (Gillespie et al., 2014) and for validating fire susceptibility indices (FSI) because of possible over or underestimation of the model performance since some large fires have several fires detections which are likely to have similar environmental conditions and spatial and temporally correlation (Schneider et al., 2008). Alternatively, Advanced Spaceborne Thermal Emission and Reflection Radiometer (ASTER) sensors with footprint of $30 \mathrm{~m}$ have been used to construct FSI using NDVI/LST of ASTER data.

Meteosat Second Generation (MSG), the new generation of geostationary meteorological satellite developed by the European Space Agency (ESA) in close corporation with the European Organisation for the Exploitation of Meteorological Satellites (EUMESAT), possesses a high temporal resolution (a near earth image every $15 \mathrm{~min}$ ) together with a spatial resolution (3 $\mathrm{km}$ at sub-satellite point) appropriate to regional to continental scales. In addition, the optical imaging radiometer on-board MSG (Spinning Enhanced Visible and Infrared Imager (SEVIRI) presents spectral capabilities that are very similar to the TIR bands around 10.8 and $12.0 \mu \mathrm{m}$ of the NOAA-AVHRR series (Peres and DaCamara, 2004). These temporal, spatial and spectral characteristics make MSG-SEVIRI suitable for retrieval of environmental parameter that change rapidly in time. Nieto et al. (2010) used MSGSEVIRI data to estimate dead fuel content in the Iberian Peninsula of Spain. The accuracy assessment showed a negative bias comparison between equivalent moisture content (EMC) of the vegetation derived from $\mathrm{T}_{\mathrm{a}}$, vapour pressure, and surface meteorological data. The remote sensed tends to underestimate the EMC from the ground. The authors recommended that improvements in $T_{a}$ and vapour pressure would lead to a better agreement between the observed and the predicted values and alternative method for estimation NDVI max that produced unbiased estimation of $T_{a}$.

Furthermore, there is mounting evidence that these optical broadband instruments have the capacity for acquiring information that has operational significant for application in fire risk 
assessment and mapping in the PA. However, other than well-known satellite optical sensor limitation of cloud-effect, these sensors (MODIS, NOAA-AVHRR, Landsat \& SPOT) lack specific windows such as red-edge which is very important band in biomass estimation particular in sparse vegetation and grassland ecosystem (Kumar et al., 2015). RapidEye with a relative high spatial resolution (5m) and 5 bands including a new band (red-edge), blue, red, green and NIR has shown a greatest capability for estimation of grassland biomass semi-arid region (Adelabu et al., 2013, Zandler et al., 2015) and hence potential for fire risk assessment. However, its applicability in monitoring fire risk conditions especially in PA is lacking. Furthermore, multispectral sensors have known limitation such as sensor saturation and absence of specific narrowband to target and highlight specific biophysical parameters (Mallinis et al., 2014), which is critical in estimation of vegetation wetness conditions for fire risk assessment. This spectrum is available in hyperspectral sensors.

\subsection{Hyperspectral remote sensing}

Advancement in remote sensing and imaging spectrometry led to the development of hyperspectral imagery which has demonstrated to be useful for the spectral and spatial discrimination of fire-related vegetation attributes such as green canopy closure, vegetation moistures, ratio dead to live plant materials and distribution of bare ground (Wang et al., 2010). Hyperspectral imagery also known as Imaging Spectrometers (IS) are instruments that have the ability to collect ample spectral information across a continuous spectrum general with 100 or contiguous spectral bands across the visible (VIS), NIR and SWIR regions of the electromagnetic spectrum, offering unprecedented detailed spectral reflectance data from land surface features. Because of its fine spectral information, hyperspectral sensors have been used for remote sensing mapping of biophysical and chemical information that is directly related to the quality of wildfire fuel including fuel type, fuel moisture, green biomass and fuel conditions (Yoon and Kim, 2003).

Kötz et al. (2004) demonstrated the potential for use of imageries from hyperspectral remote sensing in assessing and mapping wildfire risk assessment. Jia et al. (2006a) used AVIRIS data to map major forest components and fuel types by discriminating the fractional covers of photosynthetic Vegetation (PV), non-photosynthetic vegetation (nPV) and bare soil with 73,5\%, 40,3\% and 77,6\% for PV, NPV and soil respectively. These make hyperspectral remote sensing data an excellent indicator not only for fuel fractional cover but also for fuel condition after fire by greatly improving regional fire risk assessment.

Similarly, Dennison et al. (2006) illustrated the ability of hyperspectral data AVIRIS to retrieve both fire temperature and background land cover for fire spread model in wildfire risk assessment with the conclusion that fire and fuel information extracted from hyperspectral data provide the basis for eventual real-time complex fire spread model. However, the limitations of AVIRIS are that it is only available in small areas upon request and that data processing requires special expertise and software (Jia et al., 2006a). Additionally, the capability of Airborne Imaging Spectrometer data (DAIS7915 and ROSIS) to estimate structure and foliage water content of a coniferous canopy for 
fire risk assessment and fire impact management at Ofenpass Valley in the Swiss National Park have been carried out with an accuracy assessment of 71,6\% and 78,2\% for foliage water content and dry matter respectively (Kötz et al., 2004).

Yoon and Kim (2003) applied Hyperion hyperspectral remote sensing data acquired to evaluate its potential of mapping fuel properties such fuel moisture, fuel greenness, live biomass and fuel types. Although the Hyperion imagery included a lot of sensor noise and poor performance in liquid water band, the overall results showed that Hyperion imagery is useful for wildfire fuel mapping. The usefulness of hyperspectral data to recognize and map fuel type was illustrated when the highest accuracy level of $90 \%$ was achieved when comparing the MIVIS based results with ground truth data in the Pollino National Park in the south of Italy (Lasaponara et al., 2006).

Since it has been proven that the operational assessment of FMC requires high spectral resolution sensors with narrow bands to calculate vegetation dry matter content, only few studies have used the approach to estimate FMC (Hunt et al., 2012). To our knowledge, no studies have been conducted for FMC assessment using narrow bands of Hyperspectral sensors for monitoring fire risk conditions in the PAs. Hyperspectral sensors could actually provide information for estimation of FMC because due to the presence of high spectral resolution and narrow bands to which vegetation dry matter content can be retrieved. Therefore, future research for dry-matter content from narrow bands of hyperspectral sensors is needed to support this. Assumptions of greater utility of high resolution satellite imagery are widespread but its credibility has been questioned depending not only on the classification content but on image acquisition parameters and scene configuration (Carter et al., 2009). Based on the evaluation of classification results in terms of cost and technical characteristics, the use of hyperspectral datasets is suitable for use in PAs although they are still unavailable and costly for most developing countries.

\subsection{Active sensors}

Active sensors have been widely used to estimate various components of forest structures such as crown and stem biomass, foliage water content, crown bulk density and forest height that can be directly incorporated into fire risk assessment (Saatchi et al., 2007). Furthermore, it has be used as an effective solution for overcoming the limitation on providing information on conditions at the top of canopy especially in densely vegetated regions (Arroyo et al., 2008). It is employed to estimate fuel height which is critical both in fuel load assessment and fuel discrimination and it provide information of surface fuels when they are covered by forested canopy (Keane et al., 2001).

Several studies have demonstrated the successful use of Light Detection and Ranging (LiDAR) system in measuring vegetation characteristics for fire risk assessment. For instance, Morsdorf et al. (2008) employed airborne laser scanner (ALS) to measure the location and geometry of individual trees and vegetation cover to quantify fire risk in the Swiss National Park in Switzerland. Riaño et al. (2007) combined LiDAR and Colour infrared Ortho images of Gestosa in Portugal for shrub height mapping. González-Olabarria et al. (2012) illustrated the operational application of LiDAR derived 
data for fire risk assessment at the landscape level. Due to its efficiency and ability to record elevation information below vegetation cover, LiDAR has been effectively used to develop Digital Elevation Models (DEM) or Digital Terrain Models (DTM) (Burns, 2012). However, its affordability would ultimately be limited by logistics costs and challenges associated with the deployment of such airborne sensor system in an African landscape (Naidoo et al., 2012).

Despite the popularity of microwave remote sensing, very few studies have utilized such data in monitoring fire risk conditions in PAs. This is as microwave sensors are less affected by atmospheric conditions and can collect information during both day and night, it will be a better option (Tanase et al., 2015). Leblon et al. (2002) demonstrated the efficacy of using Radio Detection and Ranging (RADAR) system to assess canopy and forest fuel moisture content through analysing the potential use of European Remote Sensing Satellite Synthetic Aperture Radar (ERS-SAR) backscatter for retrieving Fire Weather Index (FWI) data and FMC. The results revealed significant relationships between backscatter and the FWI, and between the rate of change in backscatter coefficient and in the LFMC. This indicate the usefulness of ERS-1 images in monitoring fuel moisture. The capability of RADAR system for monitoring forest fuel and as potential tool for forest fire risk assessment was illustrated by Saatchi et al. (2007) through the use of Airborne SAR imagery to estimate the distribution of forest biomass and canopy fuel loads in Yellow Stone National Park. The authors found good agreement between radar-generated fuel parameters and in-situ measurement with $\mathrm{r}^{2}$ value of 0.85 (canopy fuel weight), 0.84 (canopy bulk density) and 0.78 (foliage biomass). Tanase $e t$ al. (2015) study using L-band of SAR similar to ALSO PALSAR-2 radar data collected over a semiarid Australian forest employed linear regression model to relate FMC to backscatter intensity and polametric decomposition components. Their results revealed that radar system can provide similar or improved results for FMC with a value of $\mathrm{r}=0.6-0.7$ than those achieved in previous studies using optical-based VIs.

Although active sensors provide a better alternative to broadband and hyperspectral sensors, however active sensor satellite images have inherent of speckles which looks as a grainy texture due to random construction and destructive interference from multiple scattering (Chowdhury and Hassan, 2015). Other notable limitations include for instance, the right angle surface causes double bounce reflection, volume scattering may occur when radar beam penetrates the top most surface and the brightness of the image increase due to high moisture content of the target surface (Moreira et al., 2013). According to Levin and Heimowitz (2012) the radar operates under commercial mode and the revisit time period is quite long (ERS1/2). The repeat cycle is around 35 days compared to RADARsat which has only 24 days coverage which limits capturing the temporal dynamic of moisture conditions and their coverage is very small. Future research in this direction can significantly improve our understanding of vegetation conditions in response to fire risk.

The utility and potential applications of RS have been explored. However, the usefulness of RS for monitoring fire risk conditions for fire risk assessment and mapping depends on the ability of delineating fire risk conditions at the current time. Based on this, we believe that when selecting the 
source of data imagery: the data source that has a record especially from reviewed literature; ability to predict or estimate attributes (fuel types, fuel property, land use \& topography); and resolution of dependent variables are therefore fundamentals to the usefulness of RS in monitoring fire risk conditions for fire risk assessment in PA.

From this review of sensors for monitoring fire risk conditions, we strongly deduce that the "best" sensor is often more than one sensor. We suggest the application of multi-sensoral or multiresolution data approach for fire risk assessment and mapping. Because the use of multi-sensoral data together improved methods may overcome some of the problems that are faced with single dataset.

\section{Remote Sensing Techniques for Wildfire Risk Mapping}

Generally, the usefulness of remote sensing in fire risk assessment depends not only on the data type sources, but also on effective image processing techniques. Therefore, pre-processing imagery prior to information extraction in order to eliminate data registration errors and to increase interpretability of the image is essential. Image pre-processing involves series of operation including but not limited to bad lines replacement, geometric and radiometric corrections, image enhancement and masking as well as geo-referencing. Image classification is defined as the process of extracting different classes or themes from raw remotely-sensed data (Xie et al., 2008). Numerous classification algorithms are available for different data types and conditions. The traditional pixel-based classification method, relying on spectral information works well with medium to coarse resolution images but is often found insufficient when applied to very high-resolution imagery and LiDAR (Arroyo et al., 2006). Pixel-based classification algorithms tend not to be ideal to extract information desired from the data exhibiting high frequency components with high contrast and horizontal layover of objects (Wang et al., 2010).

Object-based classification methods based on both spectral and contextual information have been shown to improve the performances of many applications, including fuel type mapping for fire risk assessment (Arroyo et al., 2006). However, the implementation of contextual information in classification is a complex process (Chen et al., 2004). The application of advance classifier such as Artificial Neural Network (ANN) can also improve image classification (Satir et al., 2016). Empirical and physical-based methods or techniques have also been used to estimate parameters (vegetation water content in this case) showing different results and accuracies among different ecosystems. The former uses statistics to construct relationship between fields measured FMC or input variables data and spectral measures based on reflectance data (Yebra et al., 2008). Physical-based approaches estimate FMC by attempting to simulate the processes that occur in the fuel thereby comparing the observed reflectance of every pixel to those simulated in a look up table, assigning to each pixel the parameters of the most similar simulated spectrum (Yebra et al., 2013). Chuvieco et al. (2009) used logistic regression models to establish ignition point (IP) of live grasses and shrubs fuels for fire risk assessment. Results revealed clear variation in FMC values of grassland and shrubs for discriminating difference groups of periods, with FMC of grassland more sensitive to the number of fires and burnt 
area as well as a good estimator of large fires. Jurdao et al. (2012) explored different empirical methods to convert LFMC into IP at Iberian Peninsula of Spain taking into account the climate and vegetation functional type using non-parametric significance tests, histograms and percentiles, classifications tress, and Logistic Regression models for estimating IP form FMC. Logistic regression analysis outperformed other models since it uses several predictor values to compute a continuous probability of IP.

Yebra et al. (2008) compared the performance of empirical and Radiative Transfer Models (RTM) approaches of Mediterranean vegetation species from MODIS reflectance measurement with the aim of developing an operational methodology of FMC estimation for fire risk assessment. The physical based on simulated data (leaf level PROSPECT and canopy level SAILH RTM) for grassland and shrublands according to their biophysical parameter traits and FMC range. Both models offer the similar accuracy level with better determination coefficient for grasslands $\left(R^{2}=0.90\right.$ and $R^{2}=0.894$ respectively than for shrublands $\left(\mathrm{R}^{2}=0.732\right.$ and $\left.\mathrm{R}^{2}=0.894\right)$.

Furthermore, statistical classifier and image transformation techniques have been applied for land use classification and vegetation or fuel type classification for fire risk assessment. Image transformation techniques are frequently applied to multidate imagery that has been stacked in $2 \mathrm{n}$ dimensional space (i.e.) Principal Component Analysis (PCA) and Tasseled Cap Transformation (TCP). TCP approach was employed on Landsat-ETM derived Wetness and Brightness Indices to assess the risk of intensive fire propagation in a National Park named Niokola Koba, Senegal West Africa (Mbow et al., 2004). The results revealed that TCP method is suited for an operative use for management of fire in savanna ecosystems. PCA is a helpful technique that is used to produce uncorrected output bands, to segregate noise components and to reduce the dimensionality of data sets (Wang et al., 2010). Mutlu et al. (2008) applied PCA to the LiDAR-QuickBird stack imagery and Minimum Noise Fraction (MNF) transform stack imagery to assess fuel models. The study revealed that PCA techniques provide accurate estimates of surface fuel parameters effectively and accurately over extensive areas of forest.

Due to the sub-pixel issue associated with medium to coarse spatial resolution of operation satellite system like Landsat, a number of image analysis accommodating mixing problems exits with fire risk assessment (Gitas et al., 2012). Support Vector machines (SVMs) are non-parametric linear classifiers that delineate the optimal separating hyperplane between classes by focusing on pixels that lie at the edge of the class distributions with the rest of the training sample effectively being discarded (Mallinis and Koutsias, 2012). Mallinis et al. (2014) used SVM classification approach in order to discriminate and map Mediterranean fuel types. However, the McNemar's test indicated that the overall accuracy differences between the produced fuel types map were not significant. Although SVM is complex and time consuming method (Hussain et al., 2013), it has the crucial ability to detect low cover fractions, which remains challenge to conventional approaches. Spectral Mixing Analysis (SMA) addressed this issue by quantifying the sub-pixel fraction of cover of different endmembers, which are assumed to be representing the spectral variability among the dominant terrain features. Jia 
et al. (2006b) applied SMA to discriminate forest cover for prediction of fire spread in California, USA.

Other techniques have been used to combine remote sensing and GIS data into decision level fire risk zone map and demonstrated their potential capabilities. For example, knowledge-based techniques, Artificial Neural Network (ANN) (Alonso-Betanzos et al., 2003, Satir et al., 2016), Bayesian belief networks (BBNs) (Bashari et al., 2016, Dlamini, 2011), Analytic Hierachy Process (AHP) (Ajin et al., 2016, Chavan et al., 2012). Alonso-Betanzos et al. (2003) applied a neural network approach for the prediction of forest fire risk in Galicia. The results indicated the system perform satisfactory with sensivity of 0,857 . In their method to resolve the uncertainity in wildfire prediction, Bashari et al. (2016) used BBNs to identify the factors influencing fire in arid and semi arid of Iran, which has significantly supported the process of adaptive management.

\section{Conclusion}

The objective of this manuscript was to review different remote sensing data and techniques that have been used for predicting and monitoring fire risk conditions and its implication for fire risk assessment in PAs. The review indicated that numerous fire risk indicators have been introduced, however, in general Vegetation Greenness-related indices (based on chlorophyll absorption) such as NDVI, EVI and SAVI and Vegetation water related indices (based on water absorption) such as NDWI, NDMI and GVMI are the most commonly used indices for quantifying fire risk conditions with NDVI \& NDWI at the top of the list.

Overall, remotely sensed data, ranging from Broadband, Hyperspectral and active (LiDAR and Radar) have shown great potentials in monitoring fire risk indicators or variables for fire risk assessment at all scale. Based on their stress-free acquisition and accessibility, broadband Multispectral data have been found to be more effective for monitoring fire risk conditions at regional scale. However, mixed pixels and sensor saturation problem have been reported with these data in fire risk assessment for complex environments. Furthermore, the absence of red-edge and narrow bands to target and highlight specific biophysical parameters such as vegetation dry matter content and biomass estimation which are critical for fire risk assessment.

Furthermore, and for remote sensing approaches to be useful for fire risk assessment in PAs, the study suggest should be conducted not for research purpose only but also should be useful at the operational level. Moreover, the specific remote sensing tools and products as well the results should be communicated to the general decision-making body in a non-technical manner. Lack of error values evaluation uncertainty of the outcomes in the majority of the RS studies is a critical issue that often prevent stakeholders to trust RS data and techniques for conservation assessment in PAs (Petrou et al., 2015). Hence, fusion of multisensory and multiresolution data might overcome problems faced by single dataset and has the potential to improve fire risk assessment and mapping in PAs. 


\section{Acknowledgement}

The authors will like to acknowledge the National Research Foundation for funding the study under the Thuthuka funding tool (UID 106921).

\section{References}

Adelabu, S, Mutanga, O, Adam, E \& Cho, MA 2013, Exploiting machine learning algorithms for tree species classification in a semiarid woodland using RapidEye image, Journal of Applied Remote Sensing, 7, 1, 073480-073480.

Aghakouchak, A, Farahmand, A, Melton, FS, Teixeira, J, Anderson, MC, Wardlow, BD \& Hain, CR 2015, Remote sensing of drought: Progress, challenges and opportunities, Reviews of Geophysics, 53, 452 -480.

Aguado, I, Chuvieco, E, Borén, R \& Nieto, H 2007, Estimation of dead fuel moisture content from meteorological data in Mediterranean areas. Applications in fire danger assessment, International Journal ofWildland Fire, 16, 390-397.

Aguado, I, Chuvieco, E, Martin, P \& Salas, J 2003, Assessment of forest fire danger conditions in southern Spain from NOAA images and meteorological indices, International Journal of Remote Sensing, 24, 8, 1653-1668.

Ajin, RS, Ana-Maria, L, Mathew, KJ, Vinod, PG \& Krishnamurthy, RR 2016, The Risk Assessment Study of Potential Forest Fire in Idukki Wildlife Sanctuary using RS and GIS Techniques, International Journal of Advanced Earth Science and Engineering, 5, 1, 308 -318.

Akther, MS \& Hassan, QK 2011, Remote sensing-based assessment of fire danger conditions over boreal forest, Selected Topics in Applied Earth Observations and Remote Sensing, IEEE 4, 992-999.

Alonso-Betanzos, A, Fontenla-Romero, O, Guijarro-Berdiñas, B, Hernández-Pereira, E, Inmaculada Paz Andrade, MA, Jiménez, E, Luis Legido Soto, J \& Carballas, T 2003, An intelligent system for forest fire risk prediction and fire fighting management in Galicia, Expert Systems with Applications, 25, 4, 545-554.

Aretano, R, Semeraro, T, Petrosillo, I, De Marco, A, Pasimeni, MR \& Zurlini, G 2015, Mapping ecological vulnerability to fire for effective conservation management of natural protected areas, Ecological Modelling, 295, 163-175.

Arroyo, LA, Healey, SP, Cohen, WB, Cocero, D \& J.A., M 2006, Using object-oriented classification and high-resolution imagery to map fuel types in a Mediterranean region, Journal of Geophys. Res.,, 111,

Arroyo, LA, Pascual, C \& Manzanera, JS 2008, Fire models and methods to map fuel types:The role of remote sensing, Forest Ecology and Management, 256, 1239 - 1252.

Ballester, MY 2007, Operational Remote Sensing in fire prevention: an Overview, TOWARDS AN OPERATIONAL USE OF REMOTE SENSING IN FOREST FIRE MANAGEMENT, 15.

Banu, T, Banu, C \& Banu, C 2014, GIS-based assessment of fire risk in National Park Domogled-Cerna Valley, Journal of Horticulture, Forestry and Biotechnology, 18, 2, 52-56.

Barroso, C \& Monteiro, I 2010, Monitoring Vegetion from Space. EUMeTRAIN, viewed 03 March 2015, $<$ http://www.eumetrain.org/data/3/36/print.htm>.

Bashari, H, Naghipour, AA, Khajeddin, SJ, Sangoony, H \& Tahmasebi, P 2016, Risk of fire occurrence in arid and semi-arid ecosystems of Iran: an investigation using Bayesian belief networks, Environmental Monitoring and Assessment, 188, 9, 1-15.

Bisquert, A, Sánchez, JM \& Caselles, V 2014, Modeling Fire Danger in Galicia and Asturias (Spain) from MODIS Images, Remote Sensing, 6, 540 -554.

Bond, WJ, Woodward, FI \& Midgley, GF 2005, The global distribution of ecosystems in a world without fire, New Phytologist, 165, 2, 525-538. 
Brown, JK \& Smith, JK 2002, Wildland fire in ecosystem- effect of fire on flora. CO: Department of Agriculture Rock Mountain Research.

Burns, J 2012, Applications of LIDAR in Wildlife Management: an opportunity in British Columbia,

Calle, A \& Casanova, JL 2008, Forest Fires and Remote Sensing, Integration for Environmental Security, $247-290$.

Carter, GA, Lucas, KL, Blossom, GA, Lassitter, CL, Holiday, DM, Mooneyhan, DS, Fastring, DR, Holcombe, TR \& Griffith, JA 2009, Remote sensing and mapping of tamarisk along the Colorado river, USA: a comparative use of summer-acquired Hyperion, Thematic Mapper and QuickBird data, Remote Sensing, $1,3,318-329$.

Ceccato, P, Gobron, N, Flasse, S, Pinty, B \& Tarantola, S 2002, Designing a spectral index to estimate vegetation water content from remote sensing data: Part 1: Theoretical approach, Remote Sensing of Environment, 82, 2, 188-197.

Chavan, ME, Das , KK \& Suryawanshi, RS 2012, Forest fire risk zonation using Remote Sensing and GIS in Huynial watershed, Tehri Garhwal district, UA, International Journal of Basic and Applied Research, 02, 7, 6-12.

Chen, D, Stow, D \& Gong, P 2004, Examining the effect of spatial resolution and texture window size on classification accuracy: an urban environment case, International Journal of Remote Sensing, 25, 11, 2177 2192.

Chowdhury, EH \& Hassan, QK 2015, Operational perspective of remote sensing-based forest fire danger forecasting systems, ISPRS Journal of Photogrammetry and Remote Sensing, 104, 224-236.

Chuvieco, E, Cocero, D, Aguado, I, Palacios, A \& Prado, E 2004, Improving burning efficiency estimates through satellite assessment of fuel moisture content, Journal of Geophysical Research: Atmospheres (1984-2012), 109, D14,

Chuvieco, E, Riano, D, Aguado, I \& Coppin, P 2002, Estimation of fuel moisture content from multitemporal analysis of Landsat Thematic Mapper reflectance data: Applications in Fire danger assessment, International Journal of Remote Sensing, 23, 11, 2145-2162.

Chuvieco, EE, González, I, Verdú, F, ; Aguado, I \& Yebra, M 2009 Prediction of fire occurrence from live fuel moisture content measurements in a Mediterranean ecosystem., International Journal of Wildland Fires 18, 430-441.

Dalponte, M, Bruzzone, L, Vescovo, L \& Gianelle, D 2009, The role of spectral resolution and classifier complexity in the analysis of hyperspectral images of forest areas, Remote Sensing of Environment, 113, $11,2345-2355$.

Dennison, PE, Charoensiri, K, Roberts, DA, Peterson, SH \& Green, RO 2006, Wildfire temperature and land cover modeling using hyperspectral data, Remote Sensing of Environment, 100, 212 -222.

Dimitrakopoulos, A \& Bemmerzouk, A 2003, Predicting live herbaceous moisture content from a seasonal drought index, International Journal of Biometeorology, 47, 2, 73-79.

Dlamini, WM 2011, Application of Bayesian networks for fire risk mapping using GIS and remote sensing data, GeoJournal, 76, 3, 283-296.

Erten, E, Kurgun, V \& Musaoglu, N 2004, Forest Fire Risk zone mapping form satellite immagery and GIS A case study. Turkey: Institute of Information.

Falkowski, MJ, Gessler, P, Morgan, P, Smith, AMS \& Hudak, AT 2004, Evaluating Aster Satellite Imagery And Gradient Modeling For Mapping And Characterizing Wildland Fire Fuels. USDA Forest Service

Food and Agricultural Organisation, F 2007, Fire management-global assessment 2006. Rome: FAO.

Gao, B 1996, NDWI- Normalized difference water index for remote sensing of vegetation liquid, Remote Sensing of Environment, 58, 322 - 331.

Gillespie, TW, Willis, K \& Ostermann-Kelm, S 2014, Spaceborne remote sensing of the world's protected areas, Progress in Physical Geography, 0309133314561648. 
Gitas, I, Mitri, G, Veraverbeke, S \& Polychronaki, A 2012, Advances in Remote Sensing of Post-Fire Vegetation Recovery Monitoring - A Review. In: (Ed., DLF (ed.) Remote Sensing of Biomass - Principles and Applications,. InTech, viewed 03 March 2015

$<\quad$ http://www.intechopen.com/books/remote-sensing-of-biomass-principles-and-applications/advancesinremote-sensing-of-post-fire-monitoring-a-review $>$.

Gitelson, A, Stark, R, Grits, U, Rundquist, D, Kaufman, Y \& Derry, D 2002, Vegetation and soil lines in visible spectral space: a concept and technique for remote estimation of vegetation fraction, International Journal of Remote Sensing, 23, 13, 2537-2562.

González-Olabarria, J-R, Rodríguez, F, Fernández-Landa, A \& Mola-Yudego, B 2012, Mapping fire risk in the Model Forest of Urbión (Spain) based on airborne LiDAR measurements, Forest Ecology and Management, 282, 149-156.

Huete, A, Didan, K, Miura, T, Rodriguez, EP, Gao, X \& Ferreira, LG 2002, Overview of the radiometric and biophysical performance of the MODIS vegetation indices, Remote sensing of environment, 83, 1, 195213.

Huete, AR 1988, A soil-adjusted vegetation index (SAVI), Remote sensing of environment, 25, 3, 295-309.

Huete, AR 2012, Vegetation indices, remote sensing and forest monitoring, Geography Compass, 6, 9, $513-$ 532.

Huete, AR, Post, DF \& Jackson, RD 1984, Soil spectral effects on 4-space vegetation discrimination, Remote sensing of environment, 15, 2, 155-165.

Hunt, ER, Wang, L, Qu, JJ \& Hao, X 2012, Remote sensing of fuel moisture content from canopy water indices and normalized dry matter index, Journal of Applied Remote Sensing, 6, 1, 061705-061705.

Hunt, JRE \& Rock, NE 1989, Detection of Changes in Leaf Water Content Using Near-and Midle-infrared Reflectances, Remote Sensing to Environment, 30, 43-54,

Hussain, M, Chen, D, Cheng, A, Wei, H \& Stanley, D 2013, Change detection from remotely sensed imgas. From Pixel-based to object-based approaches, Journal of Photogrammetry and Remote Sensing, 80, 91106.

International Union for Conservation of Nature (Iucn) 2015, What is a protected areas? : IUCN, viewed 01 October 2015, <http://www.iucn.org/about/work/programmes/gpap home/pas gpap/ >

Jhariya, MK \& Raj, A 2014, Effects of wildfires on flora, fauna and physico-chemical properties of soil-An overview, Journal of Applied and Natural Science, 6, 2, 887-897.

Jia, GJ, Burke, IC, Kaufmann, MR, Goetz, AFH, Kindel, BC \& Pu, Y 2006a, Estimates of forest canopy fuel attributes using hyperspectral data, Forest Ecology and Management 229, 27-38.

Jia, JG, Burke , IC, Goetz, AFH, Kaufmann, MR \& Kindel, BC 2006b, Assessing spatial patterns of forest fuel using AVIRIS data, Remote Sensing of Environment, 102, 318 -327.

Jurdao, S, Chuvieco, E \& Arevalillo, JM 2012, Modelling fire igntion probability from satellite estimates of live fuel moisture content, Fire Ecology, 8, 1, 77 -94.

Keane, RE, Burgan, R \& Van Wagtendonk, J 2001, Mapping wildland fuels for fire management across multiple scales: Integrating remote sensing, GIS, and biophysical modeling, International Journal of Wildland Fire, 103, 301-319.

Keetch, JJ \& Byram, GM 1968, A drought index for forest fire control,

Kötz, B, Schaepman, M, Morsdorf, F, Bowyer, P, Klaus Itten, K \& Allgöwer, B 2004, Radiative transfer modeling within a heterogeneous canopy for estimation of forest fire fuel properties, Remote Sensing of Environment 92, 332 -344.

Kumar, L, Sinha, P, Taylor, S \& Alqurashi, AF 2015, Review of the use of remote sensing for biomass estimation to support renewable energy generation, Journal of Applied Remote Sensing, 9, 1, 097696097696. 
Lasaponara, R, Lanorte, A \& Pignatti, S 2006, Characterization and Mapping of Fuel Types for the Mediterranean Ecosystems of Pollino National Park in Southern Italy by Using Hyperspectral MIVIS Data, Earth Interactions, 10, 1-11.

Leblon, B 2005, Monitoring Forest Fire Danger with Remote Sensing, NaturalHazards, 343-359.

Leblon, B, Bourgeau-Chavez, L \& San-Miguel-Ayanz, J 2012, 'Use of Remote Sensing in Wildfire Management'. Sustainable Development- Authoritative and Leading Edge Content for Environmental Management. Intech.

Leblon, B, Kasischke, E, Alexander, M, Doyle, M \& Abbott, M 2002, Fire Danger Monitoring Using ERS-1 SAR Images in the Case of Northern Boreal Forests, Natural Hazards, 27, 231-255.

Levin, N \& Heimowitz, A 2012, Mapping spatial and temporal patterns of Mediterranean widlfires from MODIS, Remote densing of Environment, 126, 12-26.

Li, Z-L, Tang, R, Wan, Z, Bi, Y, Zhou, C, Tang, B, Yan, G \& Zhang, X 2009, A review of current methodologies for regional evapotranspiration estimation from remotely sensed data, Sensors, 9, 5, 38013853.

Lozano, JF, Suárez-Seoane, S \& De Luis, E 2007, Indices derived from multi-temporal Landsat data for fire occurrence probability modelling, Remote Sensing of Environment, 107, 533-544.

Mallinis, G, Galidaki, G, ; \& Gitas, I 2014, A Comparative Analysis of EO-1 Hyperion, Quickbird and Landsat TM Imagery for Fuel Type Mapping of a Typical Mediterranean Landscape, Remote Sensing, 6, 16841740.

Mallinis, G \& Koutsias, N 2012, Comparing ten classification methods for burned area mapping in a Mediterranean environment using Landsat TM satellite data, International journal of remote sensing, 33, 14, 4408-4433.

Manzo-Delgado, L, Aguirre-Gomez, R \& Alvarez, R 2004, Multitemporal analysis of land surface temperature using NOAA-AVHRR: preliminary relationships between climatic anomalies and forest fires, International Journal of Remote Sensing, 25, 20, 4417-4424.

Maselli, F, Romanelli, S, Bottai, L \& Zipoli, G 2003, Use of NOAA-AVHRR NDVI images for the estimation of dynamic fire risk in Mediterranean areas, Remote Sensing of Environment 86, 86, 187-197.

Mbow, C, Goi“Ta, K \& Be'Nie', GB 2004, Spectral indices and fire behavior simulation for fire risk assessment in savanna ecosystems, Remote Sensing of Environment, 91, 1-13.

Mildrexler, DJ, Zhao, M, Heinsch, FA \& Running, SW 2007, A new satellite-based methodology for continental-scale disturbance detection, Ecological Applications, 17, 1, 235-250.

Moran, M, Clarke, T, Inoue, Y \& Vidal, A 1994, Estimating crop water deficit using the relation between surface-air temperature and spectral vegetation index, Remote sensing of environment, 49, 3, 246-263.

Moreau, S, Bosseno, R, Gu, XF \& Baret, F 2003, Assessing the biomass dynamics of Andean bofedal and totora high-protein wetland grasses from NOAA/AVHRR, Remote Sensing of Environment, 85, 4, 516529.

Morsdorf, F, Koetz, B \& Allgöwer, B Year, 'Published. LIDAR remote sensing and imaging spectrometry for wildfire risk assessment and forest management', Proceedings of Young Scientists in contest (YSC) " $a$ special conference on research in the Canton of Grisons, 2008.

Mutlu, M, Popescu, SC, Curt Stripling, C \& Spencer, T 2008, Mapping surface fuel models using lidar and multispectral data fusion for fire behavior, Remote Sensing of Environment, 112, 274-285.

Nagendra, H, Lucas, R, Honrado, JOP, Jongman, RH, Tarantino, C, Adamo, M \& Mairota, P 2013, Remote sensing for conservation monitoring: Assessing protected areas, habitat extent, habitat condition, species diversity, and threats, Ecological Indicators, 33, 45-59.

Naidoo, L, Cho, M, Mathieu, R \& Asner, G 2012, Classification of savanna tree species, in the Greater Kruger National Park region, by integrating hyperspectral and LiDAR data in a Random Forest data mining environment, ISPRS Journal of Photogrammetry and Remote Sensing, 69, 167-179. 
Nieto, H, Aguado, I, Chuvieco, E \& Sandholt, I 2010, Dead fuel moisture estimation with MSG-SEVIRI data. Retrieval of meteorological data for the calculation of the equilibrium moisture content, Agricultural and Forest Meteorology, 150, 7, 861-870.

Pausas, JG \& Paula, S 2012, Fuel shapes the fire-climate relationship: evidence from Mediterranean ecosystems, Global Ecology and Biogeography, 21, 11, 1074-1082.

Pereira, P, Mierauskas, P, Ubeda, X, Mataix-Solera, J \& Cerda, A 2012, Fire in Protected Areas-the Effect of Protection and Importance of Fire Management, Environmental Research, Engineering and Management, $59,1,52-62$.

Peres, LF \& Dacamara, CC 2004, Land surface temperature and emissivity estimation based on the twotemperature method: sensitivity analysis using simulated MSG/SEVIRI data, Remote Sensing of Environment, 91, 3, 377-389.

Petrou, ZI, Manakos, I \& Stathaki, T 2015, Remote sensing for biodiversity monitoring: a review of methods for biodiversity indicator extraction and assessment of progress towards international targets, Biodiversity and conservation, 24, 10, 2333-2363.

Pinty, B \& Verstraete, M 1992, GEMI: a non-linear index to monitor global vegetation from satellites, Vegetatio, 101, 1, 15-20.

Prosper-Laget, V, Douguedroit, A \& Guinot, J 1995, Mapping the risk of forest fire occurrence using NOAA satellite information, EARSeL Advances in Remote Sensing, 4, 30-38.

Rahimzadeh-Bajgiran, P, Omasa, K \& Shimizu, Y 2012, Comparative evaluation of the Vegetation Dryness Index (VDI), the Temperature Vegetation Dryness Index (TVDI) and the improved TVDI (iTVDI) for water stress detection in semi-arid regions of Iran, ISPRS Journal of Photogrammetry and Remote Sensing, 68, 1-12.

Riaño, D, Chuvieco, E, Ustin, SL, Salas, J, Rodríguez-Pérez, JR, Ribeiro, LM, Viegas, DX, Moreno, JM \& Helena Fernández, H 2007, Estimation of shrub height for fuel-type mapping combining airborne LiDAR and simultaneous color infrared ortho imaging, International Journal of Wildland Fire, 16, 341 -348.

Riaño, D, Vaughan, P, Chuvieco, E, Zarco-Tejada, PJ \& Ustin, SL 2005, Estimation of fuel moisture content by inversion of radiative transfer models to simulate equivalent water thickness and dry matter content: analysis at leaf and canopy level, Geoscience and Remote Sensing, IEEE Transactions on, 43, 4, 819-826.

Rollins, MG, Keane, RE \& Parsons, RA 2004, Mapping fuels and fire regimes using remote sensing, ecosystem simulation, and gradient modelling, Ecological Applications, 1, 14, 75-95.

Saatchi, S, Halligan, K, Despain, DG \& Crabtree, RL 2007, Estimation of forest fuel load from radar remote sensing, Geoscience and Remote Sensing, IEEE Transactions on, 45, 6, 1726-1740.

Sandholt, I, Rasmussen, K \& Andersen, J 2002, A simple interpretation of the surface temperature/vegetation index space for assessment of surface moisture status, Remote Sensing of environment, 79, 2, 213-224.

Sannier, C, Taylor, J \& Plessis, WD 2002, Real-time monitoring of vegetation biomass with NOAA-AVHRR in Etosha National Park, Namibia, for fire risk assessment, International Journal of Remote Sensing, 23, 1, 71-89.

Satir, O, Berberoglu, S \& Donmez, C 2016, Mapping regional forest fire probability using artificial neural network model in a Mediterranean forest ecosystem, Geomatics, Natural Hazards and Risk, 7, 5, 16451658.

Schneider, P, Roberts, DA \& Kyriakidis, PC 2008, A VARI-based relative greenness from MODIS data for computing the Potential Index, Remote Sensing of Environment, 112, 1151-1167.

Sow, M, Mbow, C, Heley, C, Fensholt, R \& Sambou, B 2013, Estimation of Herbaceous fuel moisture content using vegetation indices and land surface temperature for Modis data, Remote Sensing, 5, 2617 - 2638.

Stow, D, Niphadkar, M \& Kaiser, J 2005, MODIS-derived visible atmospherically resistant index for monitoring chaparral moisture content, International Journal of Remote Sensing, 26, 17, 3867-3873. 
Tanase, M, Panciera, R, Lowell, K \& Aponte, C 2015, Monitoring live fuel moisture in semiarid environments using L-band radar data, International Journal of Wildland Fire, 24, 4, 560-572.

Van Wagtendonk, JW, Root, RRXIJO \& Remote Sensing, 1639-1651, 2003, The use of multi-temporal Landsat Normalized Difference Vegetation Index (NDVI) data for mapping fuel models in Yosemite National Park, USA, Internatiobal Journal of Remote Sensing, 24, 8, 1639 -1651.

Van Wilgen, BW, Govender, N, Forsyth, GG \& Kraaij, T 2011, Towards adaptive fire management for biodiversity conservation: Experience in South African National Parks, koedoe, 53, 2, 96-104.

Verbesselt, J, Jönsson, P, Lhermitte, S, Van Aardt, J \& Coppin, P 2006a, Evaluating satellite and climate dataderived indices as fire risk indicators in savanna ecosystems, Geoscience and Remote Sensing, IEEE Transactions on, 44, 6, 1622-1632.

Verbesselt, J, Somers, B, Van Aardt, J, Jonckheere, I \& Coppin, P 2006b, Monitoring herbaceous biomass and water content with SPOT VEGETATION time-series to improve fire risk assessment in savanna ecosystems, Remote Sensing of Environment, 101, 3, 399-414.

Verbesselt, P, Fleck, S \& Coppin, P 2002, Estimation of fuel moisture content towards fire risk assessment. Rotterdam: Millpress.

Vidal, A \& Devaux-Ros, C 1995, Evaluating forest fire hazard with a Landsat TM derived water stress index, Agricultural and forest meteorology, 77, 3, 207-224.

Vidal, A, Pinglo, F, Durand, H, Devaux-Ros, C \& Maillet, A 1994, Evaluation of a temporal fire risk index in Mediterranean forests from NOAA thermal IR, Remote Sensing of Environment, 49, 3, 296-303.

Vorster, WA \& Jordaan, M 2014, ' Assessment and Analysis of Wildfires with the Aid of Remote Sensing and GIS', 10th International Conference of the African Association of Remote Sensing of the Environment, 2014, 32.

Wang, J, Sammis, TW, Gutschick, VP, Gebremicheal, M, Dennis, SO \& Harrison, RE 2010, Review of Satellite Remote Sensing Use in Forest Health Studies, The Open Geopgraphy Journal, 3, 28-42.

Wang, K, Franklin, SE, Guo, X \& Cattet, M 2010, Remote Sensing of Ecology, Biodiversity and Conservation: A Review from the Perspective of Remote Sensing Specialists., Sensors, 10, 9647 -9667.

Wang, L, Qu, JJ \& Hao, X 2008, Forest fire detection using the normalized multi-band drought index (NMDI) with satellite measurements, Agricultural and Forest Meteorology, 148, 11, 1767-1776.

Wang, L, Zhou, Y, Zhou, W \& Wang, S 2013, Fire danger assessment with remote sensing: a case study in Northern China, Nat Hazards, 65, 819-834.

Willis, KS 2015, Remote sensing change detection for ecological monitoring in United States protected areas, Biological Conservation, 182, 233-242.

Xie, Y, Sha, Z \& Yu, M 2008, Remote sensing imagery in vegetation mapping: a review, Journal of plant ecology, 1, 1, 9-23.

Yebra, M, Chuvieco, E \& Rian0, D 2008, Estimation of live fuel moisture content from MODIS images for fire risk assessment, Agr i c u l t u r a l and Fore s t Me t e orology 148, 523-536.

Yebra, M, E.;, P, Dennison, PE, Chuvieco, E, Riaño, D, Zylstra, P, Hunt Jr, ER, Danso, FM, Qi, Y \& Jurdao, S 2013, A global review of remote sensing of live fuel moisture content for fire danger assessment: Moving towards operational products, Remote densing of Environment, 136, 455 - 468.

Yoon, Y \& Kim, Y 2003, Application of Hyperion Hyperspectral Remote Sensing data for Wildfire fuel mapping, Korean Journal of Remote Sensing, 23, 1, 21-32.

Zandler, H, Brenning, A \& Samimi, C 2015, Quantifying dwarf shrub biomass in an arid environment: comparing empirical methods in a high dimensional setting, Remote Sensing of Environment, 158, 140155.

Zhang, C, Guo, X, Wilmshurst, J \& Sissons, R 2005, The evaluation of broadband vegetation indices on monitoring northern mixed grassland, Prairie Perspectives, 8, 23-36. 